\title{
LOGIC MODEL FOR MENTAL HEALTH INTERVENTIONS: THE RECOVERY COLLEGE MODEL IN QUEBEC, CANADA
}

\author{
Breitner Gomes Chaves*, MD; Catherine Briand, 0.T, Ph.D, Marie-Michele Lord, 0.T, Ph.D, \\ Joanie Thériault, O.T. Farand Lambert, MD. Ph.D and Julio Macario de Medeiros, Ph.D.
}

MD, MPH, Ph.D student from Public Health School, Université de Montréal

\section{ARTICLE INFO}

\section{Article History:}

Received $14^{\text {th }}$ April, 2021

Received in revised form

$06^{\text {th }}$ May, 2021

Accepted $11^{\text {th }}$ June, 2021

Published online $28^{\text {th }}$ July, 2021

\section{Key Words:}

Mental Health Education;

Health Evaluation; Logic Model

*Corresponding author:

Breitner Gomes Chaves

\begin{abstract}
The Recovery College ( $\mathrm{RC}$ ) model represents a worldwide innovation in health systems. First appeared in England and now established in five continents, the RC model proposes a mental health educational approach in the community, emphasizingco-production, co-learning, and equity between theoretical/clinic knowledge and experiential knowledge (1-3). All participants(individuals with or without mental health challenges, their relatives, mental health professionals, health and education service providers, citizens) have access to mental health, recovery, and well-being training(4). Both participants and trainers collectively learn and reflect on their mental health attitudes, behaviors, and practices. This article reports on the coconstruction process followed by Quebec's RC team, the first to have developed a RC logic model. The logic model conception followed six steps/strategies: 1) Participant observations, 2) Analysis of administrative documents, 3) Informal interviews and meetings with stakeholders (trainers, health service managers, and partner organizations) to better understand the implicit assumptions of the intervention, 4) Review of the literature related to the recovery college model, 5) Co-construction of causal links between resources, activities, and outcomes, 6) Validation and synthesis of the logic model. Finally, the logic model was disseminated, highlighting the relationships between the strategic resources needed for the key activities of the intervention to produce the expected outcomes.
\end{abstract}

Copyright (C) 2021, Breitner Gomes Chaves et al. This is an open access article distributed under the Creative Commons Attribution License, which permits unrestricted use, distribution, and reproduction in any medium, provided the original work is properly cited.

Citation: Breitner Gomes Chaves, Catherine Briand, O.T, Ph.D, Marie-Michele Lord, O.T, Ph.D, Joanie Thériault, O.T. Farand Lambert, Ph.D and Julio Macario de Medeiros, Ph.D. "Logic model for mental health interventions: the recovery college model in Quebec, Canada.", International Journal of Development Research, 11, (07), 48781-48784.

\section{INTRODUCTION}

The mental health sector has been undergoing considerable changes in recent decades. The health systems have been challenged to move from their traditional dichotomous mental health vision (presence VS absence of mental health diagnosis criteria) towards holistic services and practices that address the complexity of mental health issues(5). For this purpose, there is a need to re-think innovative strategies that promote individuals and local communities' autonomy to meet the modern mental health world's challenges. In that regard, the Recovery College (RC) model represents a worldwide innovation in health systems. Initially established in England and now on five continents, the RC model proposes a mental health educational approach in the community, emphasizing co-production, co-learning, and equity between theoretical/clinic knowledge and experiential knowledge (see Table 1)(1)(2,3). All participants (individuals with or without mental health challenges, their relatives, mental health professionals, health and education service providers, citizens) have access to mental health, recovery, and well-being training (4).
Table 01: Recovery College Principles and Values



Both participants and trainers collectively learn and reflect on their mental health attitudes, behaviors, and practices. The courses in RC learning centers are co-designed, co-produced, and co-facilitated by health professionals and people with experiential knowledge (peer tutors who are experts by experience) of mental health challenges and recovery (6).

In 2016, a group of researchers and partner organizations decided to implement one RC learning center in Quebec, Canada. The RC model can be considered a complex intervention in which a wide range of 
contextual determinants may dynamically interact both with the implementation process and the outcomes. Therefore, the group has created a graphic representation to illustrate the intervention's theoretical foundation for all stakeholders along the implementation process, known as the "logic model."Although the RC model is widespread throughout the world, nological model has been published to date. Health program planners use a logic model to represent the complex intervention "path of change." In other words, it is a strategy to represent in a simplified way the relationships between the mobilization of resources needed, the intervention itself, and the desired outcomes. There are several strategies and approaches to building a logic model (7-9). However, there is a significant diversity concerning detail and complexity to represent the "program theory" depending on the context, available resources, primary goals, etc. (10). Logical models can benefit intervention at least in four ways (7, 11-13): 1) it supports the planning of health interventions; 2) it helps to promote a critical reflection on the intervention program theory (that is, how the intervention intends to promote the expected changes); 3 ) it allows a visual and diagrammatic representation of the intervention, being a communication tool facilitating both the diffusion and the discussion about the intervention's needs among the interested parties (objectives, resources, activities, etc.); 4) It supports the intervention monitoring and follow-up. To sum up, the logic model makes more explicit some implicit "theories of change" of complex interventions (14). For the group of researchers and partner organizations in Quebec, constructing a logic model also allowed them to work together, co-construct a common representation, and support the paradigm shift proposed by intervention. This article reports on the co-construction process followed by Quebec's RC team, the first to have developed a RC logic model.

\section{METHODS}

The following six strategies were carried out between October 2019 and January 2020:

Participant Observations: One hundred twenty (120) hours of observations were conducted over four (4) months in Quebec's recovery college learning center. Observations included participation in trainer's training, community training, and steering committee meetings.

Analysis of administrative documents: Numerous administrative documents were read and analyzed (ex. reports and meeting minutes). The analysis allowed integrating knowledge accumulated by the learning center members during the logic model construction process.

Informal interviews and meetings with stakeholders (trainers, managers, and partners) to better understand the implicit assumptions of the intervention: The observation process allowed interaction with different parties involved in the model implementation. It enabled a better understanding and validation of certain assumptions and mechanisms implicit in the intervention. The actors involved were the trainers (people involved in co-developing the training), the managers (people responsible for managing the learning center), and members representing partner organizations.

Review of the literature related to the recovery college model: A recovery college review of the literature was consulted to facilitate understanding the RC models' program theory. The Quebec learning center research team (doctoral students and researchers) conducted the literature review, covering ten years of scientific publications on the outcomes and "mechanisms of action"(i.e., reasoning and reactions of human agents) of the RC model (15).

Co-construction of causal links between resources, activities, and outcomes: A group of Quebec learning center managers (02 people), researchers ( 02 people), and doctoral students ( 04 people) participated in four meetings to design the initial logic model. They focused on integrating the operational model of the intervention and its model of change.

Validation and synthesis of the logic model: Synthesis and the initial version of the logic model were then validated by the same actors involved in step 5 (doctoral students, managers, and researchers). Finally, the final logic model version was presented to stakeholders (including managers and organization partners) for validation.

\section{RESULTS}

An initial co-constructed version of the logic model (back-and-forth process) was finally disseminated to the Quebec recovery college learning center team members and partner organizations in January 2019.The logic model highlights the relationships between the strategic resources needed for the key activities of the intervention to produce the expected proximal, intermediate, distal, and ultimate outcomes (or changes). Figure 1 synthesizes the program theory(16) of the proposed intervention, encompassing the assumptions and explanations according to the understanding/expertise of the actors involved in the intervention and light of the scientific literature review.

\section{DISCUSSION}

Resources and process: The structure needed to set up a recovery college is more extensive than just "monetary" resources. Considering health intervention as a social action system, a health intervention structure has at least 03 dimensions: 1 ) physical dimension (mobilized resources); 2) organizational dimension (the set of management rules that define the distribution and exchange of resources); 3) symbolic dimension (the set of beliefs, representations, and values) (17). In terms of the physical dimension, partner organizations are seen as valuable resources. The choice of strategic partners has been subject to an extensive process of reflection by founders about how each organization could contribute to implementation. Building a group of strategic partners towards "an idea" has been described in scientific literature as acritical measure to influence the political agenda(18, 19). For instance, it helps to converge efforts and highlight "the problem" $(20,21)$ to decision-makers of the current mainstream mental health "paradigm". Members of these organizations do not only act mobilizing their target public. They also mobilize public opinion $(22,23)$ and act as change agents $(24-26)$ or public policy entrepreneurs $(21,26)$. Concerning the organizational dimension, the model adopts a style of decision-making participative and democratic. The focus is put on the integration of academic/clinic and experience knowledge and co-construction. On the symbolic dimension, there is an effort to embody the recovery principles (values and beliefs) at all levels of the Quebec learning center. Indeed, organizational values can drive change and support social cohesion among stakeholders $(27,28)$. By favoring a participatory and concerted decision-making process and the co-construction of the model implemented, the founders wished to support the change in practice and vision embodied in the Recovery College model. The intervention activities (process) are based on four axes, as shown in figure 1. Key intervention activities include: 1 ) identification of priority community needs to guide training co-construction (axis 01$) ; 2$ ) recruitment and training of trainers, and co-construction of the courses that will be offered by the trainers (axis 02); 3) Enrollment process and training provision (axis 03); and 4) monitoring and supporting participant outcomes and ongoing improvement processes (axis 04). Concerning the outputs, recovery colleges are not conventional learning centers, whose primary objective usually is to accomplish particular learning objectives. Therefore, the outputs aim not only to generate knowledge about mental health but also to change minds and serve as a model of an inclusive environment. The principles of the model (educational principles, co-production, co-learning, close collaboration, social inclusion, etc.) are powerful tools for transformation. In other words, while the learning center is concerned with improving participants' mental health knowledge and skills, it is also concerned with "how to do it" of providing an enabling environment for all.

Change model: A health intervention can be considered an organized system of social action that aims to change the course of a 

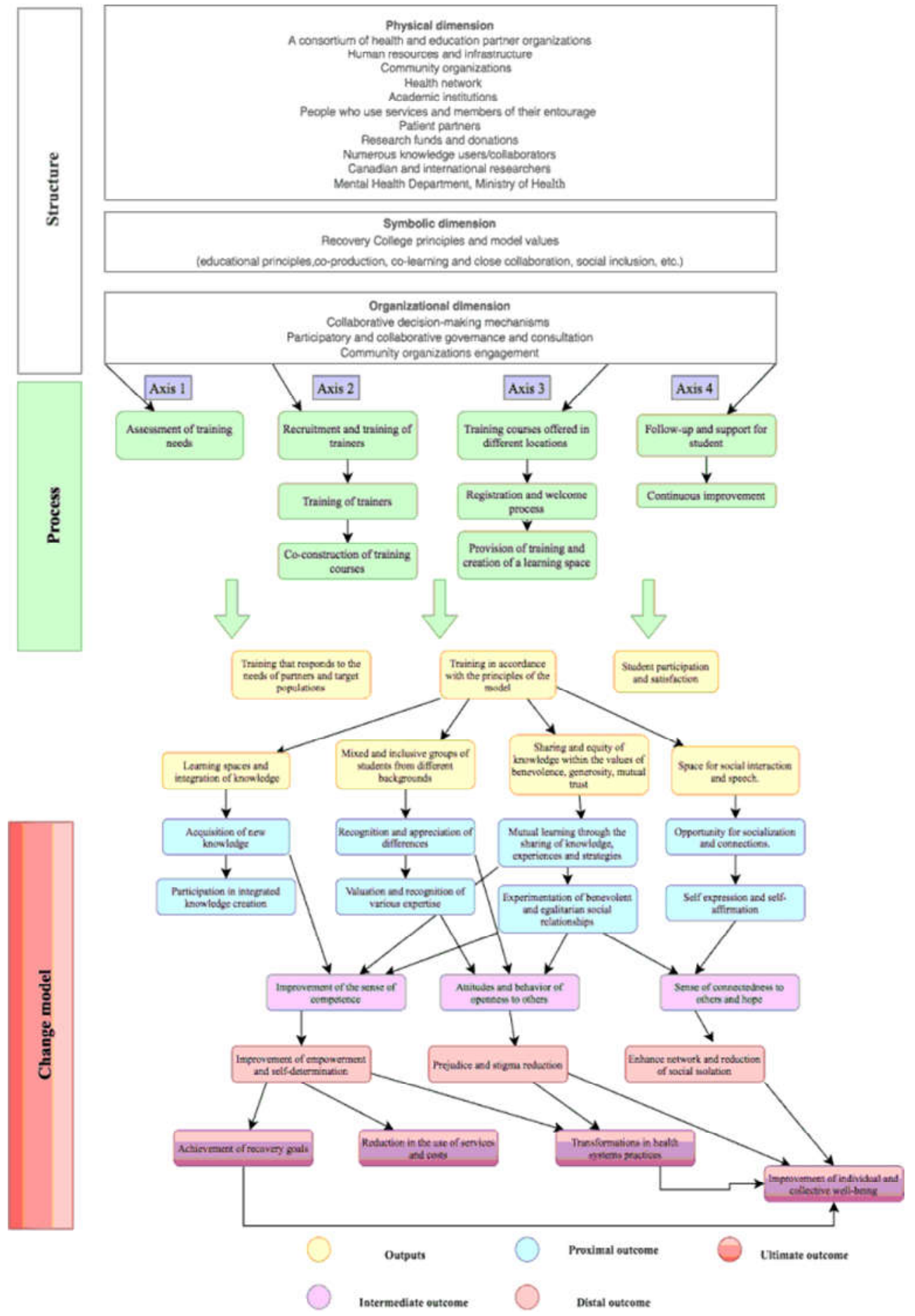

Figure 1. Quebec recovery college learning center logic model

phenomenon to correct a problematic situation in a given environment and during a given time (29). The "causal" path or change model (13, 30) links the intervention outputs to ultimate outcomes. The intervention raises "assumptions" that a series of mechanisms would lead to a process of changes, both at the individual level of the participants (ex. improving empowerment and self-determination), at the local health system level (ex. transformation of practices and services based on the recovery paradigm), and at the societal level (ex. changing prejudice and stigma). Broadly, health interventions are theories incarnate (31). Indeed, the Quebec recovery college logic model has several theoretical influences, such as self-determination theory $(32,33)$, personal recovery theories $(34-37)$, recovery-oriented practices theories (38) peer support theories $(39,40)$, active and transformative learning theories $(41)$, anti-stigma theories $(42,43))$ and self-efficacy theory (44). For instance, to foster the well-being of learners and the community (ultimate outcome), the strategy aims to promote the empowerment and self-determination of individuals and reduce prejudice and stigma among participants. In addition, these outcomes are thought to take place in an enabling environment capable of increasing the network of participants and their selfefficacy perception while reducing the social isolation of participants. The intervention logic model also aims to support ongoing evaluative research on the intervention outcomes on participants, allowing the visualization of the outcomes to be measured. Finally, other logic model benefices are: 1) since the logical model provides an original "path of change" generated by the innovative mental health model, it can contribute to future learning centers' planning (or continued improvement); 2) a participative approach to logistic models' coconstruction can bring several benefits to the intervention implementation process, and several authors have shown some advantages in implicating stakeholders from the beginning $(7,9,45$, 46).

\section{CONCLUSION}

The recovery model is in full expansion around the world. The Logic model presented in the paper is the first to propose several interconnected mechanisms that explain "how" some RC outcomes are 
supposed to be reached by recovery colleges. Also, it may provide insights to the recovery college community about "how" the RC learning centers would "work." However, further evaluative research should test the theoretical model's validity. A thorough understanding of the mechanisms of action is needed to capture the "how to do it" and transform practices. More studies are also needed to explain how contextual factors (ex. cultural, political, and organizational determinants) can influence RC models' implementation and outcomes. In this regard, theory-driven approaches, such as realistic evaluation or implementation analysis, may help advance the model's program theory development.

\section{REFERENCES}

1. Perkins R, Repper J, Rinaldi M, Brown H. 1. 2012. Recovery Colleges.

2. Crowther A, Taylor A, Toney R, Meddings S, Whale T, Jennings $\mathrm{H}$, et al. 2019. The impact of Recovery Colleges on mental health staff, services and society. Epidemiol Psychiatr Sci., 28(5):481-8.

3. Meddings S, McGregor J, Roeg W, Shepherd G. 2015. Recovery colleges: quality and outcomes. Mental Health and Social Inclusion.

4. Meddings S, Campbell E, Guglietti S, Lambe H, Locks L, Byrne D, et al., 2018. Editors. From service user to student-the benefits of recovery college. Clinical Psychology Forum; 2015.

5. Patel V, Saxena S, Lund C, Thornicroft G, Baingana F, Bolton P, et al. The Lancet Commission on global mental health and sustainable development. The Lancet. 392(10157):1553-98.

6. Perkins R, Meddings S, Williams S, Repper J. 2018. Recovery colleges 10 years on. Nottingham: ImROC.

7. Champagne F, Brousselle A, Hartz Z, Contandriopoulos A, Denis J. 2009. Modéliser les interventions. L'évaluation: concepts et méthodes. 57-70.

8. Chen WW, Cato BM, Rainford N. 1999. Using a logic model to plan and evaluate a community intervention program: A case study. International Quarterly of Community Health Education., 18(4):449-58.

9. Renger R, Titcomb A. 2002. A Three-Step Approach to Teaching Logic Models. American Journal of Evaluation. 23(4):493-503.

10. Astbury B, Leeuw FL. 2010. Unpacking Black Boxes: Mechanisms and Theory Building in Evaluation. American Journal of Evaluation., 31(3):363-81.

11. McLaughlin JA, Jordan GB. 1999. Logic models: a tool for telling your programs performance story. Evaluation and Program Planning., 22(1):65-72.

12. McLaughlin JA, Jordan GB. 2004. Using logic models. Handbook of practical program evaluation. 2:7-32.

13. Chen HT, Chen H-T. 2005. Practical program evaluation: Assessing and improving planning, implementation, and effectiveness: Sage.

14. Baxter SK, Blank L, Woods HB, Payne N, Rimmer M, Goyder E. 2014. Using logic model methods in systematic review synthesis: describing complex pathways in referral management interventions. BMC Medical Research Methodology. 14(1):62.

15. Thériault J, Lord M-M, Briand C, Piat M, Meddings S. 2020. Recovery Colleges After a Decade of Research: A Literature Review. Psychiatric Services. appi. ps. 201900352.

16. Chen H-T. 1989. The conceptual framework of the theory-driven perspective. Evaluation and Program Planning. 1989;12(4):3916.

17. Brousselle A, Champagne F, Contandriopoulos A-P, Hartz Z. 2011. L'évaluation: concepts et méthodes: Deuxième édition: Les Presses de l'Université de Montréal.

18. Jenkins-Smith HC, Nohrstedt D, Weible CM, Sabatier PA. 2014. The advocacy coalition framework: Foundations, evolution, and ongoing research. Theories of the policy process., 3:183-224.

19. Mintrom M, Vergari S. 1996. Advocacy coalitions, policy entrepreneurs, and policy change. Policy studies journal., 24(3):420-34.

20. Baumgartner FR. 2001. Agendas: Political. In: Smelser NJ, Baltes PB, editors. International Encyclopedia of the Social \& Behavioral Sciences. Oxford: Pergamon; p. 288-91.
21. Kingdon JW, Stano E. 1984. Agendas, alternatives, and public policies: Little, Brown Boston.

22. Burstein P. 2003. The Impact of Public Opinion on Public Policy: A Review and an Agenda. Political Research Quarterly., 56(1):29-40.

23. Rounce AD. 2004. Editor Political actors' perceptions of public opinion: assessing the impact of opinion on decision making. Prepared for the Canadian Political Science Association's Annual Meeting, Winnipeg, Manitoba, June.

24. Havelock RG. 1973. The change agent's guide to innovation in education: Educational Technology.

25. Rogers EM. 2010. Diffusion of innovations: Simon and Schuster.

26. Schneider M, Teske P, Mintrom M. 2011. Public entrepreneurs: Agents for change in American government: Princeton University Press.

27. Greenwood R, Hinings CR. 2017. Understanding strategic change: The contribution of archetypes. Academy of management Journal.

28. Schein EH. 2010. Organizational culture and leadership: John Wiley \& Sons.

29. François Champagne A-PC, Astrid Brousselle, Zulmira Hartz et Jean-Louis Denis. L'évaluation dans le domaine de la santé: concepts et méthodes. In: Montréal Ud, editor. L'évaluation: concepts et méthodes. 2e éd. ed. Montréal2011.

30. Chen HT. 2012. Theory-driven evaluation: Conceptual framework, application and advancement. Evaluation von Programmen und Projekten für eine demokratische Kultur: Springer; p. 17-40.

31. Patton MQ. 1999. Book Review: Realistic Evaluation. American Journal of Evaluation;20(2):385-8.

32. Ryan R. 2009. Self determination theory and well being. Social Psychology. 84(822):848.

33. Ryan RM, Deci EL. 2017. Self-determination theory: Basic psychological needs in motivation, development, and wellness: Guilford Publications.

34. Jacob KS. 2015. Recovery model of mental illness: a complementary approach to psychiatric care. Indian $J$ Psychol Med., 37(2):117-9.

35. Leamy M, Bird V, Le Boutillier C, Williams J, Slade M. 2011. Conceptual framework for personal recovery in mental health: systematic review and narrative synthesis. The British Journal of Psychiatry., 199(6):445-52.

36. Lunt A. 2002. A theory of recovery. Journal of psychosocial nursing and mental health services. 40(12):32-9.

37. Shepherd G, Boardman J, Slade M. 2008. Making recovery a reality: Citeseer.

38. Shepherd G, Boardman J, Burns M. 2010. Implementing recovery. A methodology for organisation change London: Sainsbury Centre for Mental Health.

39. Barton J, Henderson J. 2016. Peer support and youth recovery: a brief review of the theoretical underpinnings and evidence. Canadian Journal of Family and Youth/Le Journal Canadien de Famille et de la Jeunesse. 8(1):1-17.

40. Dennis C.L. 2003. Peer support within a health care context: a concept analysis. International Journal of Nursing Studies., 40(3):321-32.

41. Mezirow J. 2018. Transformative learning theory. Contemporary theories of learning: Routledge. p. 114-28.

42. Brohan E, Slade M, Clement S, Thornicroft G. 2010. Experiences of mental illness stigma, prejudice and discrimination: a review of measures. BMC Health Services Research. 10(1):80.

43. Thornicroft G. 2006. Shunned: Discrimination against people with mental illness: Oxford university press Oxford.

44. Bandura A. 1977. Self-efficacy: toward a unifying theory of behavioral change. Psychological review. 84(2):191.

45. Tremblay C, Coulombe V, Briand C. 2017. Users' involvement in mental health services: programme logic model of an innovative initiative in integrated care. International Journal of Mental Health Systems. 11(1):9.

46. Chaves BG, Briand C, Bouabida K. 2021. Innovation in Healthcare Organizations: Concepts and Challenges to Consider. International Journal of Health Research and Innovation. 9(1). 